\title{
AUTOMATED DRILLING FOR INSTALLATIONS INSIDE THE CROSSRAIL TUNNELS
}

\author{
J. Douglas ${ }^{1}$, T.A. Kelly ${ }^{2}$ and S. Jain ${ }^{3}$ \\ ${ }^{I}$ Alstom Transport UK, London, United Kingdom \\ ${ }^{2}$ Costain, London, United Kingdom \\ ${ }^{3}$ Enable My Team/MobiBiz Ltd., London, United Kingdom
}

\begin{abstract}
In 2014 the authors were presented with the challenge of procuring and commissioning the machines and software for the automation of the drilling of all 250,000 fixings for the services, walkway and overhead catenary in more than 40 kilometres of bored tunnel for the Crossrail project. The challenge was to resolve the complex interface with the tunnel segments that can significantly slow down manual drilling at site. Automation would mitigate health and safety impacts on the workforce of drilling a quarter of a million holes, many upside down and at height. The project would utilize state of the art laser scanning, development of innovative software that solved all the drilling permutations to satisfy required layouts and, not least, involve the manufacture in Switzerland of two mammoth drilling machines suited to the bored tunnel environment. The authors will demonstrate how pointcloud data, combined with state-of-the-art processing power and bespoke software, calculated final layouts used by the drilling machine guidance systems. The logic used by the computer program to optimise the drilling will be laid out and discussed along with the format of the outputs for the machine guidance. The operating principals of the two machines will also be explained in order to demonstrate the level of automation achieved. Special focus will be given to the guidance systems, how they were validated, and the accuracies achieved. Reports on the production achieved on site will be presented. Finally, some conclusions about the potential and limitations of this technology will be discussed.
\end{abstract}

\section{Introduction}

The installation of bracketry to support M\&E (Mechanical and Electrical) services and OHLE (Overhead Line Equipment) within the newly constructed Crossrail tunnels presented an opportunity for proactive engineering on a live construction programme enabling the authors to develop the automated tunnel drilling machines. The extremely repetitive and labourintensive task of drilling more than 250,000 holes into the precast concrete segmental lining to enable anchoring of the bracketry along more than $40 \mathrm{~km}$ of bored tunnel sections that make up the Crossrail route suits an automated solution ideally on both technical and H\&S (Health and Safety) grounds.

The physical factors that make the task appropriate to the development of a smart automated construction technique are:

- Relatively constant geometry of the work space

- Relatively constant requirement for hole positions

- Scale of the work enabling cost benefits to be realised

Not only does the work lend itself well to the development of an automated solution from a technical undertaking but there are also significant $\mathrm{H} \& \mathrm{~S}$ risks associated with manual methods of completing the works, which can be significantly reduced through use of a machine-based application, most significantly reduction of construction operatives' exposure to:

- Hand Arm Vibration whilst operating vibrating tools such as hammer drills which can ultimately result in a life changing condition which reduces dexterity of operatives, preventing them from being able to undertake simple everyday tasks, for example fastening of buttons.

- Silica dust generated during the drilling of concrete segments which can result in long term health problems including lung diseases such as lung cancer; silicosis; chronic obstructive pulmonary disease; asthma and, in some cases, death.

- Working at height presenting a risk of operatives sustaining serious injury or death through either a fall from height or from being contacted by materials falling from height.

- Musculoskeletal injuries sustained from works in awkward position particularly where operatives need to drill holes in the crown of the tunnel requiring works above the head and at extended reach to drill into the sides of the tunnel.

Whilst solving the health and safety challenge through use of a machine is relatively self-explanatory, in that the machine carries out the physical works, thus removing a significant proportion of operative exposure, the technical solution here is somewhat more complex.

This paper sets out to describe the solution used for automated drilling, the challenges faced, and the results achieved.

To fully understand the technical challenge, it is first important to set out the basic principles of both the tunnel lining 
construction and services bracketry design that form the requirements for the positioning and drilling of holes.

\section{Tunnel lining construction}

The Crossrail tunnels are constructed using a pre-cast concrete segmental lining system to form a $6.2 \mathrm{~m}$ internal diameter tunnel.

The segments are nominally $1.6 \mathrm{~m}$ wide pre-cast $300 \mathrm{~mm}$ thick steel-fibre reinforced concrete to grade C50/60. Steel reinforcement bar was only used in some sections of the tunnels where there were extreme load cases such as in areas of floating track slab for high attenuation of noise and vibration. The proportion of the tunnels containing steel reinforced sections of the Crossrail tunnels formed a very low percentage of the route and in these areas a manual method of drilling was used to enable the lining to be scanned and the holes drilled to avoid the reinforcement.

The lining is constructed using rings, each formed of eight segments. These consist of three different segment types termed here as; Standard segments, Shoulder or Counter Key Segments and Key Segments. Each of these segments has several features, the significance of which for the drilling application is discussed later. See Figure 1. These features are:

- Grout hole in the centre of the segment

- Cast in sockets for bolting of longitudinal joints

- Radial (Longitudinal) Joint

- Circumferential Joints

Figure 1: Segment types and features

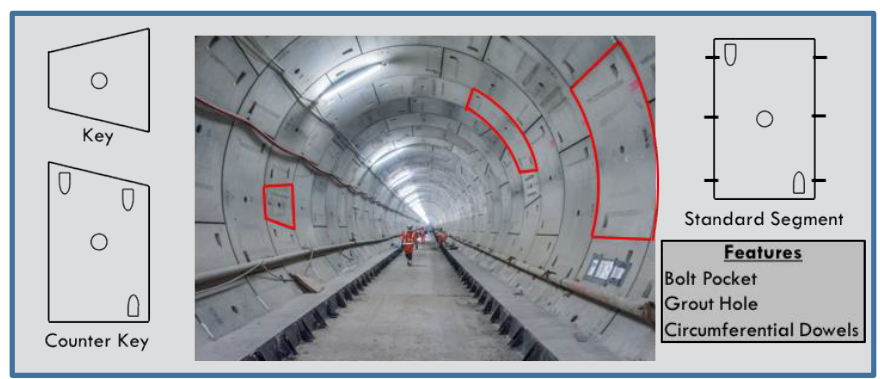

\subsection{Construction process and arrangement}

During the construction of the Tunnel and within the works of the Tunnel Boring Machines the segments are placed in the sequence; five standard segments followed by the two shoulder segments and finally locked together with the key to form a pattern like the representative example shown in Figure 2.

Obtaining the curvature of the tunnels without compromising the waterproofing between rings and segments requires a slight taper across the diameter of the ring. This taper enables the tunnel to be gradually pitched and turned during construction by rotating the rings as shown indicatively in figure 3 . The figure provides an exaggerated example of how tapers can work to provide straight and curved sections of tunnel in twodimensional space, but the principle applies to threedimensional space equally.
Figure 2: An indicative section and developed view of the tunnel lining construction

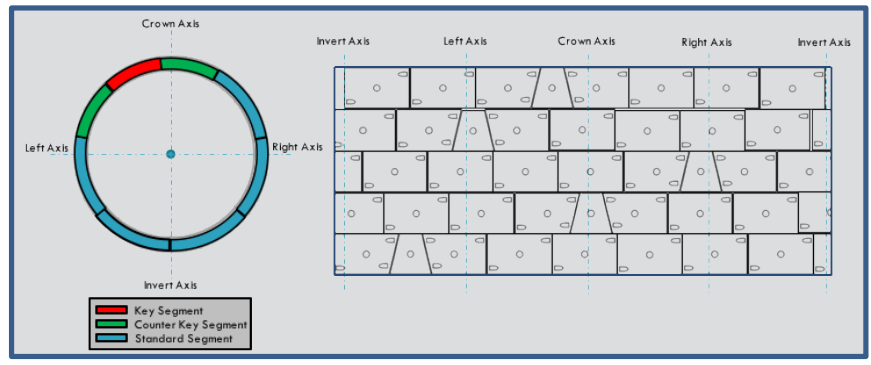

Figure 3: Dimensional example of the use of tapered rings to achieve tunnel curvature

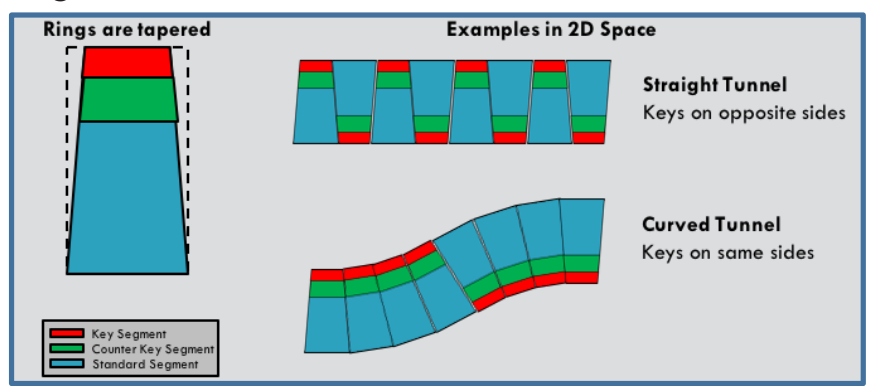

\subsection{Complexities and other factors in tunnel construction}

There are further intricacies with the tapering of rings and in fact there were more than 20 possible orientations that each ring could take relative to the previous. In addition, during tunnel construction, the machine and the rings will often incrementally roll round due to various pressures and this phenomena can aggregate to hundreds of millimetres of difference from nominal positions of the segments in the ring assembly.

These orientations and phenomena are relevant to the automated drilling application as they result in a tunnel that has an almost infinite number of possible locations of the radial (longitudinal) joints in the tunnel lining which in turn is critically important in the definition of locations of "no-drill zones" as defined below.

\subsection{No-drill zones}

To maintain the structural integrity of the segments and prevent any risk to the waterproofing of the segments a $150 \mathrm{~mm}$ zone around each of these features was defined as an area within which it is not permissible to drill, termed here as "no-drill zones". Holes could also not exceed $150 \mathrm{~mm}$ in depth (half of the $300 \mathrm{~mm}$ thickness of the segments). See Figure $4 \mathrm{a}$. To visualise this figure $4 \mathrm{~b}$ highlights these no-drill zones in the hatched area onto an unfolded view of what an indicative short section of tunnel may look like. 
Figure 4a: Shaded areas show areas of the standard segment types occupied by the no-drill zones

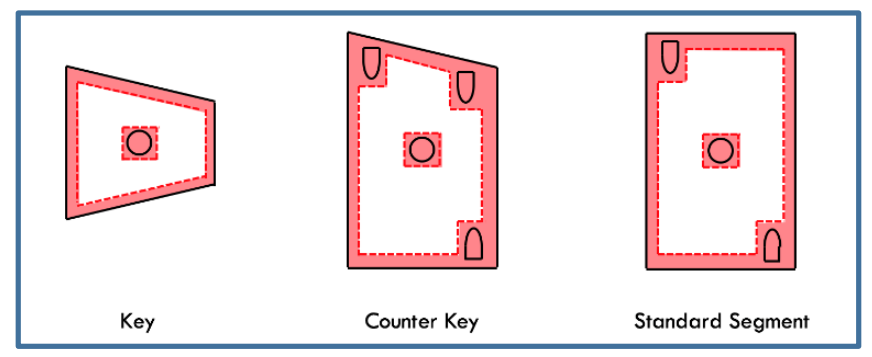

Figure $4 \mathrm{~b}$ : A representative view on the tunnel lining demonstrating the significant quantity of surface area occupied by no-drill zones.

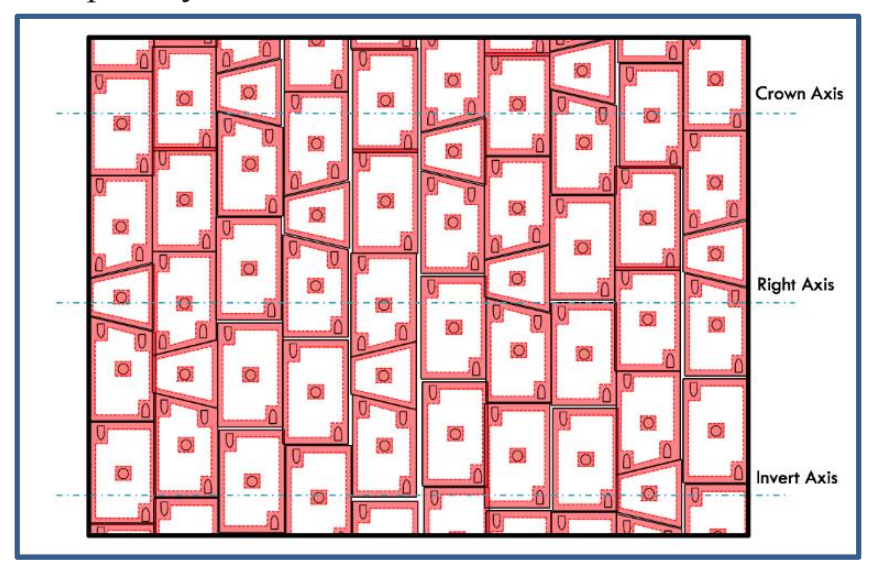

Thus determination of the "no-drill zone" locations in a reference system allowing easy comparison with the design location of the installations was critical to enable the successful execution of the drilling activity, automated or not. Past experience had shown that manual drilling teams could not be expected to avoid no drill zones without guidance or setting out and that re-planning of intervals and patterns 'on-the-fly' was extremely risky and time-consuming.

\section{Previous experience on High Speed One}

In 2005 a similar challenge had presented itself with the London sections of the Channel Tunnel Rail Link (CTRL), better known as UK High Speed One. As part of clearance studies the bored tunnels had been scanned and data extracted for cross sections. The resolution of the scanning had been identified as good enough to detect the positions of the segmental lining and a project to map certain segments and plan the overhead catenary drilling was implemented.

Using a first generation of techniques that this paper will detail later for the Crossrail application drilling maps were developed for the overhead catenary installations. The accuracy of these maps was high $(5 \mathrm{~mm})$ but production involved a long process of pointcloud "modelling": The process of manually overlaying lines on the pointcloud in CAD. An example of one of the drilling maps is in figure 5 .
Figure 5: CTRL OHLE drilling map

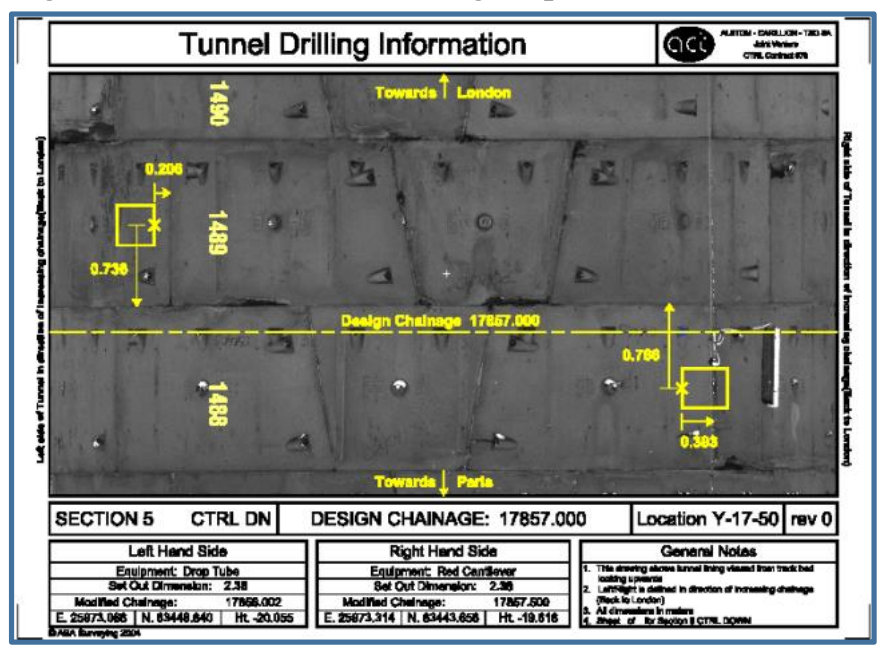

Although the trial and error element of positioning for the drilling was obviated using this method the points still then needed to be set out and marked on site. The project was seen as a qualified success, proved data capture by scanning was already efficient and accurate but demonstrated an over reliance on manual extraction in the modelling phase that would have benefited from increased computer processing power and automation.

Ten years later as a result of the experiences from CTRL the tender documentation for the scanning of the Crossrail tunnels contained a number of clauses pertaining to allowable time from time of scan to time of final data delivery.

\section{Describing the problem to enable the solution}

To inform the data capture required it is necessary to draw the outline of the agreed solution for calculating the positions for drilling.

\subsection{Geometrical description of the problem}

In order to "intersect" a position of interest on the tunnel lining to a vector describing a radially mounted drill bit [so as to drill perpendicular to the circumference of the tunnel lining] it was decided to use an alignment chainage [z direction] $+2 \mathrm{D}$ polar [zenith angle and slope distance] co-ordinate system with its origin at the built Best Fit Centre (BFC) of the bored tunnel. The zenith angle and slope distance are derived from dimensions measured on $\mathrm{x}$ and $\mathrm{y}$ axes from the BFC perpendicular to $\mathrm{z}$ at any point in the tunnel. See figure 6 . A further simplification for computation is then enabled by the circular nature of the tunnel as this means the slope distance " $R$ " from the tunnel centre to any point of interest on the tunnel lining at the same chainage is always the same. A segment with corners defined by locations $\mathrm{ABCD}$ with a grout hole and cast in sockets at $B$ and $D$ can then be defined by 8 chainages $(p-w)$ and 8 angles $(\Theta 0-\Theta 7)$. 
Figure 6: Geometrical representation of positions of interest on tunnel segment $\mathrm{ABCD}$

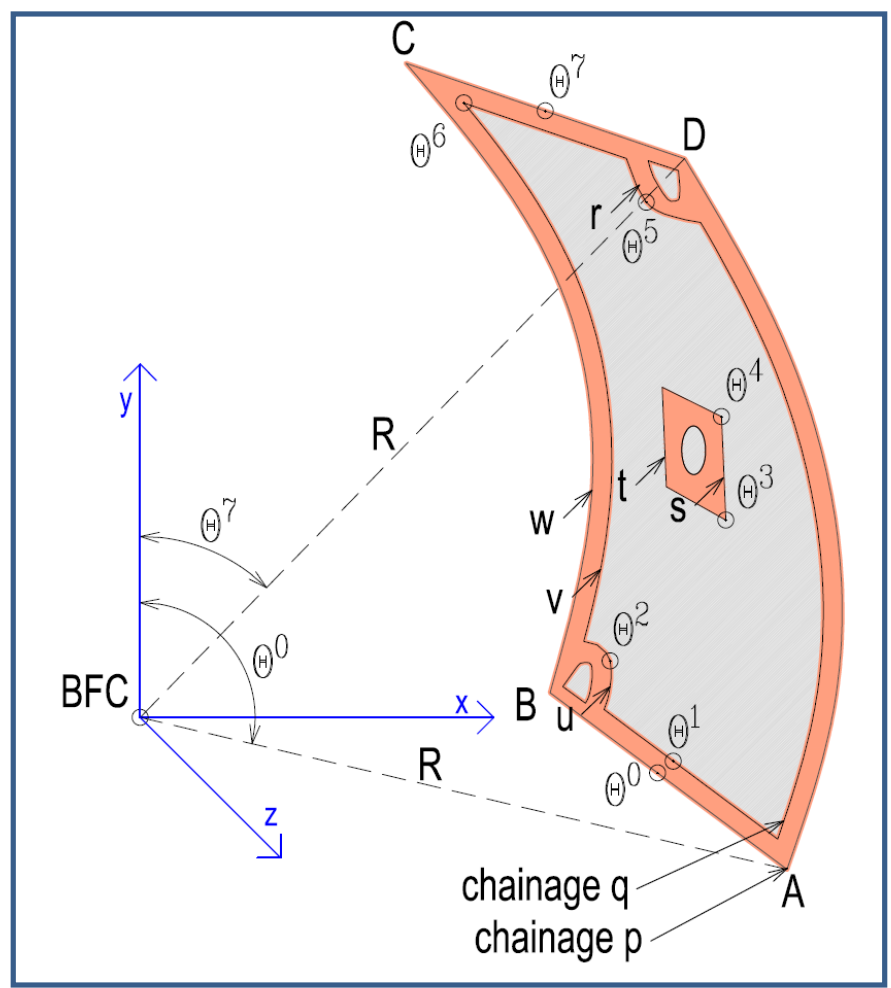

This created a two stage assessment process for a proposed drilling location with the measured data set from the scan of the segmental lining:

Considering any proposed drilling location the test for interference of the drilling point with the no drill zones defined by the tunnel segments could be made by comparing first the longitudinal proximity [in chainage direction] and then, where necessary, the proximity on the lining (described by a difference in angle from $\mathrm{x}, \mathrm{y}$ dimensions)

\subsection{Interrelationship of track alignment centreline with tunnel geometry}

The chainage $+2 \mathrm{D}$ system is a transformation of any Cartesian $\mathrm{XYZ}$ coordinate system via a series of connected geometrical elements (straights, clothoids, curves, parabolas), running through the tunnel and better known as the track alignment centreline ("alignment"), plus a defined dimensional relationship to the tunnel centre, to be known as the Design Tunnel Alignment or DTA. So there are 3 origins in cross section to consider: The track alignment centreline or SOP (Setting Out Point), the DTA and the BFC. See Figure 7. With a wriggle survey the BFC can be defined in relation to the DTA, and then in turn to the alignment. Tunnel construction tolerances defined the location of the BFC as being within 0$100 \mathrm{~mm}$ radially of the DTA (ideally zero) but the component of $\mathrm{x}$ and $\mathrm{y}$ in this radial distance was variable based upon a host of factors describing the accuracy of the tunnel driving. The alignment itself is defined in the XYZ coordinate system used by Crossrail as part of the track and tunnel design. The reason that both the BFC and the DTA remain equally important is that whilst the BFC describes where the tunnel lining is actually found the DTA remains the reference point for where the vehicle will be positioned in the tunnel via the track and in turn governs the position of the mechanical and electrical equipment that was to be installed via the drilling.

Figure 7: Track alignment centreline relationship to DTA and BFC

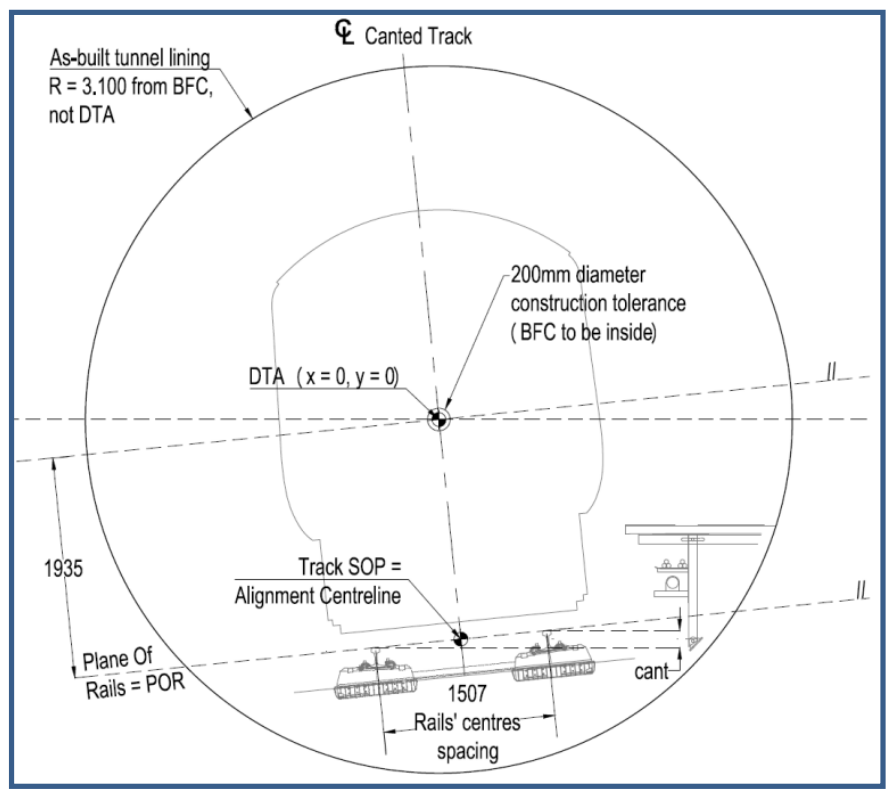

A wriggle survey is a series of well distributed points measured on the lining of the circular tunnel upon which a BFC is computed by "best-fitting". It is the classic method by which tunnel position is determined.

By now it was clear that the scanning of the bored tunnel had to deliver two things: Crossrail XYZ coordinates for a BFC for every ring and for every segment intersection on the tunnel lining. As previously mentioned, as each tunnel ring is made up of the same pattern of $1 \mathrm{Key}, 2$ Counter key, 5 Standard segments the complete no-drill zone for the entire tunnel could be developed from the segment intersection positions. It could then be assessed relative to the design layouts for the installations using the appropriate measured BFC.

\section{Scanning and modelling the tunnels}

The burden of scanning and modelling 840,000 segment intersection positions over $42 \mathrm{~km}$ of tunnels to the project delivery timescale was taken on by the chosen survey consultant, Plowman Craven Ltd.

Working with Atlas Computers Ltd., they also exploited the uniformity of the site arrangement and developed a projection routine which temporarily "unwrapped" the captured pointcloud of the circumference of the tunnel to a 2D "conformal" surface over which a 2D wireframe of the design dimensions of the segments could be overlaid. The 2D wireframe contained an "endless" unwrapped string of the eight segments that interlocked to form a ring and by matching the key location enabled a match to the imagery unwrapped 
from the pointcloud. See figure 8 . The wireframe, once matched, was then re-wrapped along with the pointcloud into $\mathrm{XYZ}$ coordinates in the Crossrail reference system.

Figure 8: Overlay of segment wireframe on "unwrapped scan"

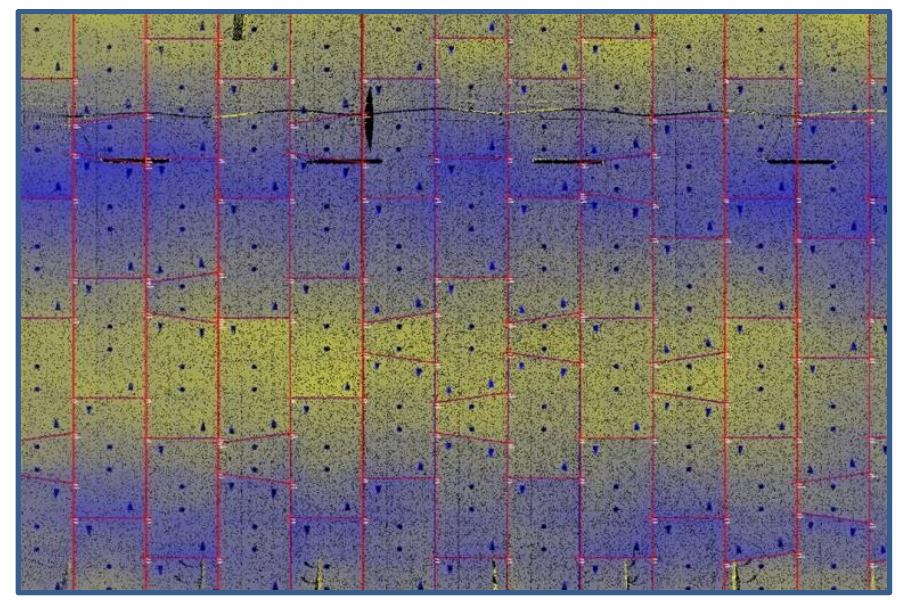

This innovation by Plowman Craven enabled a semiautomated process where the modeller was left simply with matching up the design segment wire frame with the pointcloud imagery at $1.6 \mathrm{~m}$ intervals. This led to a dramatic reduction in modelling to around 26,250 "fixes" in order to produce nearly one million segment points of interest in XYZ.

In between the data delivery from Plowman Craven and the input files for the computer program to determine the final drilling locations written by EMT (Enable My Team) was the process of transformation of XYZ to the BFC coordinate system previously described. Using Amberg Rail software with correctly imported alignments made this task straightforward. As Amberg Rail is configured to deal with pointcloud data from the Amberg GRP5000 scanning system and has an extremely robust alignment geometry calculator it had no difficulty rapidly transforming the large dataset for the segments from one reference to the other. Segment and BFC data was delivered with an identifier attribute, DTA chainage, $\mathrm{x}$ offset and y offset. Figure 9 shows ring number "00002" segment labelling for the identifier attributes.

Figure 9: Ring 00002 segment identifier attributes from the $2 \mathrm{D}$ wireframe overlay

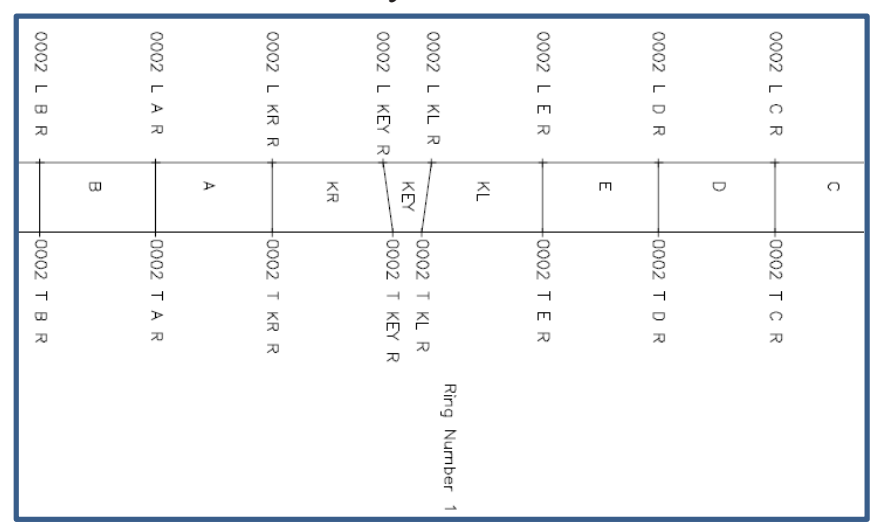

\section{EMT computer program}

EMT now developed a computer program that calculated drilling positions that satisfied the no-drilling zone criteria whilst respecting the differing parameters of the required layouts for various installations:

\subsection{Categorisation of the installations}

Installations were categorised with different tolerances and requirements as follows:

- OHLE anchors and supports

- CMS (Cable Management System) bracketry for various cables

- WW (Walkway) designed to precisely suit the position of the train vehicle

- $\quad$ ERW (Earth Return Wire) for electrical safety

See figure 10 .

Figure 10: Various installations to be installed by drilling into bored tunnel lining

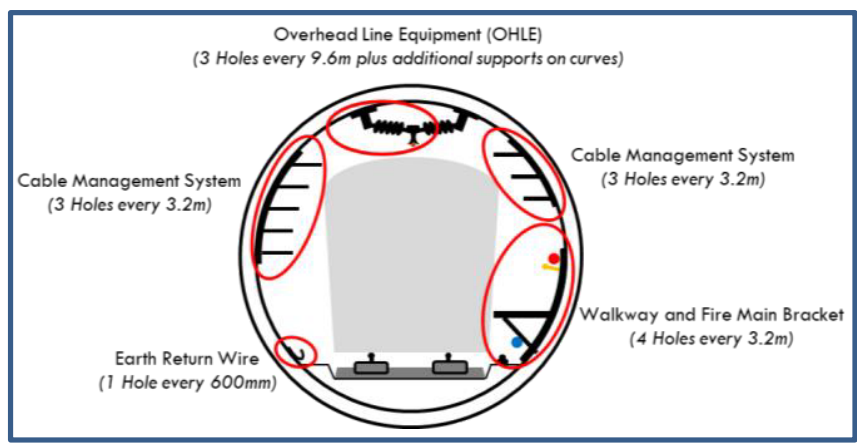

\subsection{Schedule of program inputs}

The schedule of program inputs were therefore as follows:

- $\quad$ BFC data.

- Segment edge data.

- Control points for accurate chainage reference.

- Design Track Superelevation for which installations needed to rotate around the tunnel lining in order to match the vehicle position.

- Tunnel Pitch and distance corrections for curvature information.

- A pre-defined segment types library. Required for segment type identification. Essential to create a local mapping for each segment type to identify "No-drill zone" areas. As well as the segment types already mentioned there were some special cases. For example, where two grout holes were present instead of one.

- Drilling Rule Books showing the spacing along the tunnel and the relationship to Track/DTA as defined by design drawings for the installations.

- OHLE design book showing the required configuration for section overlaps and span lengths. 
- The parameters of the drilling machine design itself were now accounted for: The simultaneous drilling permutations that were possible (which drills on, which drills off). The allowable movement of two independent arms ("stroke" in the $\mathrm{z}$ direction) relative to one another and from a stopped machine position.

\subsection{Processing and computing}

Considering a proposed start chainage and intervals the program's algorithm first detected which segment the proposed location fell within.

Then for the segment in question further tests were made to determine the proximity of the proposed point to no drill zones.

The location was then accepted or modified by certain increments in chainage or angle that fitted machine and design constraints based upon a hierarchy of rules.

The modified location was tested again and the program continued to loop back until a location was found.

For CMS, WW and ERW enough freedom in both $\mathrm{z}$ and angle was allowed to not need to loop back to the previous solved location. In general if the optimal $\mathrm{z}$ interval could not be resolved with changes in angle a "short" interval extra bracket was introduced that allowed the layout to "jump" the no drill zone. In general the co-incidence of the key segment (with the largest percentage of "no-drill" zone relative to its overall surface area) introduced the most iterating in the program's computation of the layouts.

Computation of OHLE positions were based on an input "design book" and its constraints. So called OHLE "overlaps" [allowing a continuous catenary between section ends] were computed first which, once validated, stayed fixed and drilling positions of spans in-between the overlaps were then resolved.

It should be noted at this stage that the designers and engineers of ATCjv and the machine manufacturer Rowa (Switzerland) played a significant role by crystalizing the parameters for installation for the bracketry and by innovating flexibility into the fixings' combinations for the brackets. This meant that different patterns of drilling could be tested at the same location by the EMT program. For example, the CMS brackets had eight different combinations of three holes out of eight possible locations and the WW 26 different combinations of four holes out of eight possible locations. See figure 11.

\section{Drilling machine guidance principals and machine configuration}

\subsection{Drilling machine guidance principals}

To configure the format for the EMT program outputs it was now necessary to understand the machine configuration and guidance principles.
Figure 11: Allowable drilling permutations for some of the installations

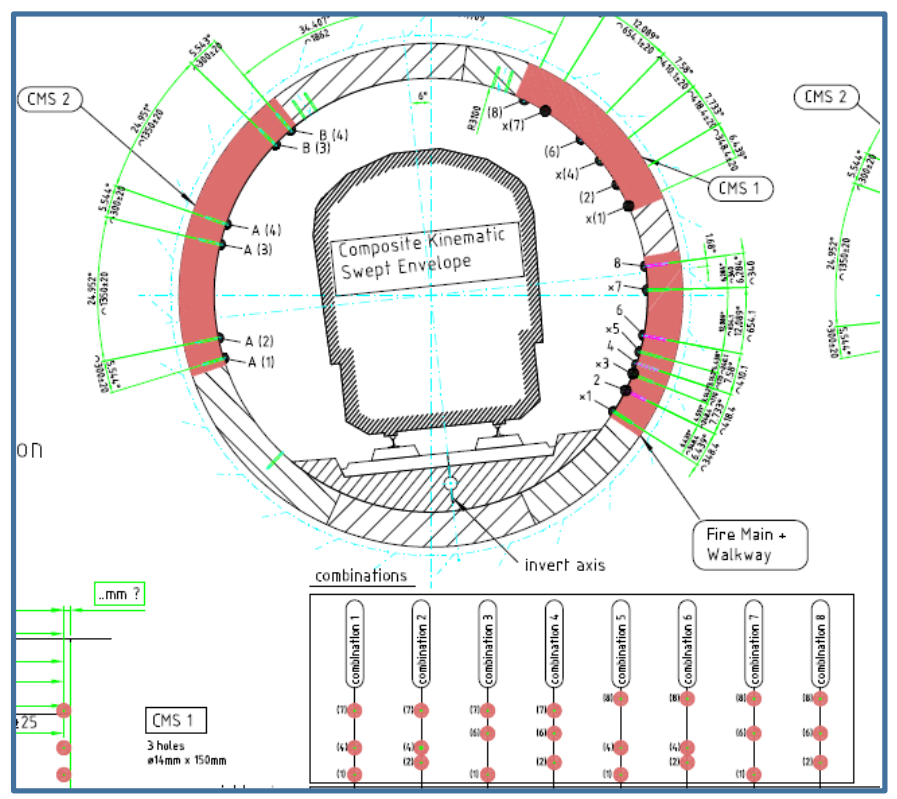

The machines were horizontally (x) centred in the as built tunnel by guide rollers extended an equal distance away from the machine centre. In addition a vertical laser measurement to the crown and hydraulics would fine adjust the vertical (y) centring. See figure 12 .

Figure 12: Drilling machine centring in the tunnel

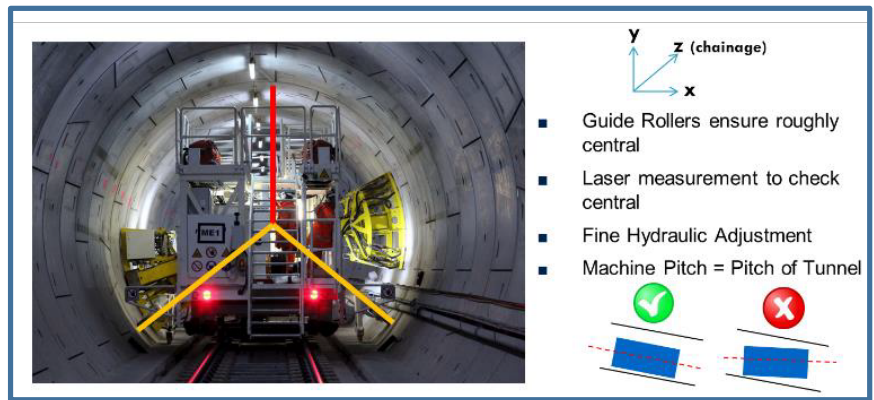

This simplified the guidance to just the $\mathrm{z}$ direction/chainage. Already, as part of the trackwork process an accurate chainage reference control point was marked on the tunnel lining (along with rail level) about every three metres. These reference points were to form the baseline position for a survey target that the machine would measure to by laser in order to determine its own chainage location. As the laser measurement distance was not on the alignment centreline corrections in the distance data for any particular drilling location from a particular target were made. In general, if the laser was on the outside of the curve the distance it needed to measure was longer and if on the inside, shorter, in order to find the correct location. See Figure 13. 
Figure 13: Guidance along the tunnel by laser

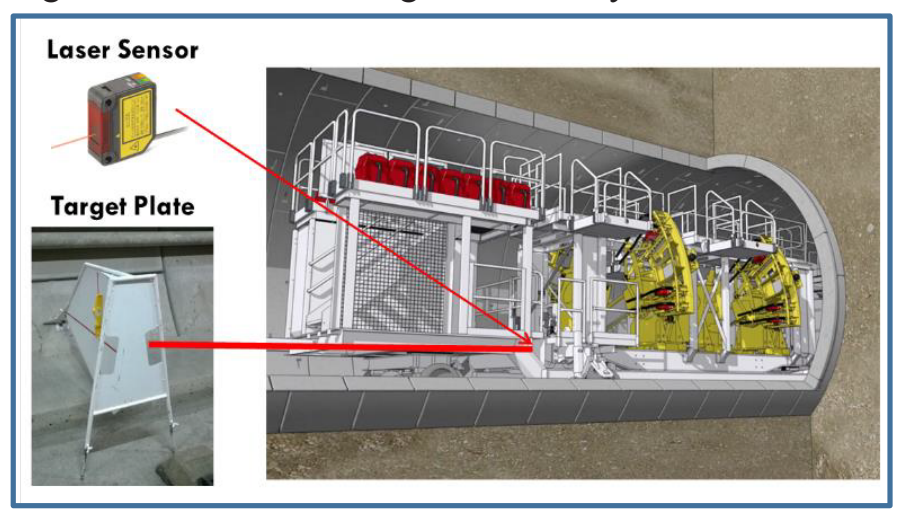

\subsection{Drilling machine configuration}

Two machines were constructed. One machine was for CMS and WW drilling operations with twin arms for both and the other with a single arm for OHLE and a double for ERW.

The twin arms could move back or forward in the $\mathrm{z}$ direction from a zero position independent of each other on the vehicle [to a known limit] so as to achieve the possibility of drilling two cross sections at once.

The arm would receive a command for the arm chainage, angle and which drills to extend. See Figure 14.

Figure 14: Drilling sequence for each arm

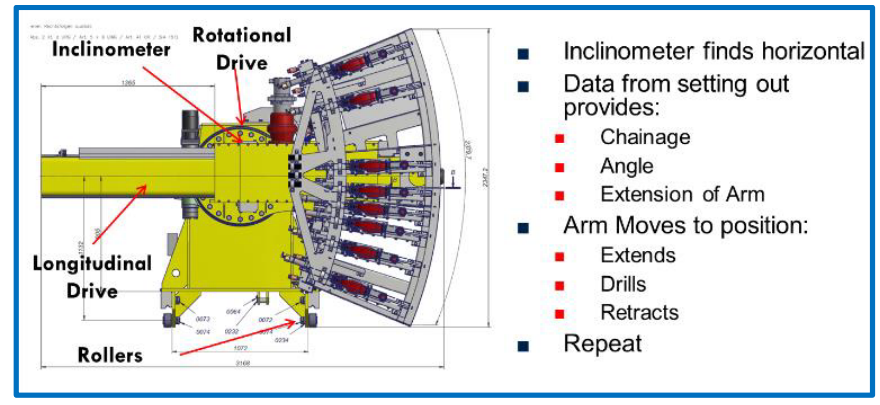

More details of the machine operation are discussed below.

\section{EMT program outputs and validation}

\subsection{Output format}

Finalised drilling locations were exported to an output text file accepted by the drilling machine operations software. Separate output files for both machines were generated for each chainage reference control point. And a separate file format was required for each machine. These files first communicated a distance in front of the control point that the machine should stop. This distance had a tolerance of some centimetres. Then, when stopped, an updated distance from the laser instructed the movements of the individual arms from the current static position of the machine when compared to the distances in the file. Next the arm angle was communicated. This angle accounted for the offsets of the various individual drill points from the arm. Then the individual drills on the arm where turned on or off. Finally an "epoch" command would inform if the action was part of the $1^{\text {st }}, 2^{\text {nd }}$ or even $3^{\text {rd }}$ movement of the arms from the same static machine position. An EMT program output example is in figure 15.

Figure 15: EMT program output

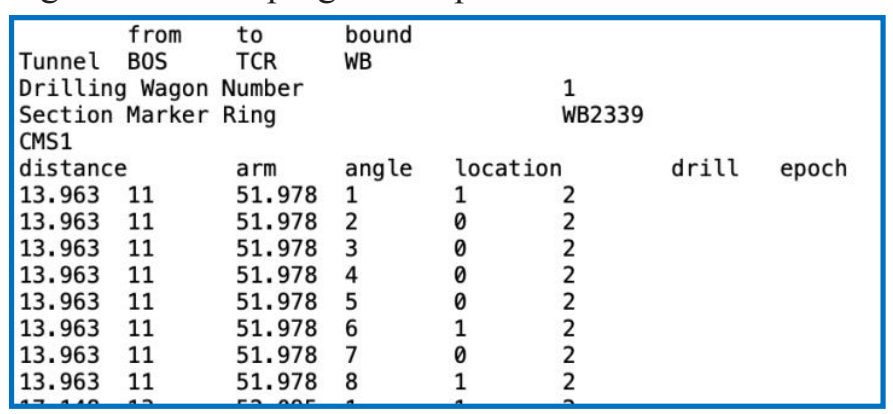

\subsection{Checks on site}

During the testing and commissioning phase in Rowa's factory in Switzerland and at the beginning of operations in tunnels the validity of the EMT outputs, plus performance of the machine and its guidance system were closely monitored by manual surveying measurements.

To convert the EMT program outputs into project chainages (z) and heights (y) for manual surveying was very straightforward using Amberg Rail software. In this exercise offsets (x) needed only to be defined in terms of left or right of alignment centreline because on site they had to intersect with the tunnel lining. With such a schedule of xyz and a total station the project survey team could accurately set out the points using on-board software and pinpoint with the instrument's co-axial laser.

Therefore before drilling a sample of calculated positions could be checked for compliance. This enabled very effective final de-bugging of the EMT calculation routines.

\subsection{Machine calibration and error propagation}

The same checking arrangement was used for final calibration of the machines and their arms. Differences between drill centres and marked positions by total station were witnessed to be in a range of $+/-10 \mathrm{~mm}$ in cross section and $+/-20 \mathrm{~mm}$ in chainage with a Normal Distribution. Errors with the total station system are, as expected, very low, at around $+/-2 \mathrm{~mm}$ in all dimensions and the majority of the differences could be assigned to machine error attributed to an aggregation of the various support systems as follows:

In $\mathrm{z}$ there was a small amount of error associated with mounting the laser target to the reference, especially in terms of the target "squareness" to the alignment in areas of tight curvature. Combined with this were the corrections for the offset of the laser to the alignment centre, as explained in 7.1. And then residuals in the movement of the drilling arms within the vehicle plus the correction for the pitch of the tunnel.

The cross-sectional differences [mainly y] were attributable to some weight distribution effects with the arms in certain rotated positions and the calibration of the inclinometer controlling the angle settings. See Figure 16. 
Figure 16: Radial [cross sectional] and chainage [z] differences found at check sections between total station set out and drill holes made by drilling machine [Thames Tunnel].

\begin{tabular}{|l|r|r|r|r|r|}
\cline { 3 - 6 } & radial & chainage & radial & chainage \\
\hline delta $[\mathrm{mm}]$ & 5 & -5 & delta $[\mathrm{mm}]$ & -3 & -20 \\
\hline delta $[\mathrm{mm}]$ & 6 & -7 & delta $[\mathrm{mm}]$ & -5 & 7 \\
\hline delta $[\mathrm{mm}]$ & 0 & 19 & delta $[\mathrm{mm}]$ & 8 & 11 \\
\hline delta $[\mathrm{mm}]$ & 4 & -2 & delta $[\mathrm{mm}]$ & -3 & -8 \\
\hline delta $[\mathrm{mm}]$ & -4 & -26 & delta $[\mathrm{mm}]$ & -9 & 11 \\
\hline delta $[\mathrm{mm}]$ & -5 & 9 & delta $[\mathrm{mm}]$ & 4 & -17 \\
\hline delta $[\mathrm{mm}]$ & 0 & -13 & delta $[\mathrm{mm}]$ & -9 & 1 \\
\hline delta $[\mathrm{mm}]$ & 8 & 11 & delta $[\mathrm{mm}]$ & 4 & 6 \\
\hline delta $[\mathrm{mm}]$ & 6 & -5 & delta $[\mathrm{mm}]$ & -6 & -11 \\
\hline delta $[\mathrm{mm}]$ & 10 & -8 & delta $[\mathrm{mm}]$ & -3 & 13 \\
\hline delta $[\mathrm{mm}]$ & 8 & -3 & delta $[\mathrm{mm}]$ & -2 & 30 \\
\hline delta $[\mathrm{mm}]$ & -7 & 1 & delta $[\mathrm{mm}]$ & 0 & 6 \\
\hline delta $[\mathrm{mm}]$ & -5 & -4 & delta $[\mathrm{mm}]$ & -2 & -12 \\
\hline delta $[\mathrm{mm}]$ & 5 & 1 & delta $[\mathrm{mm}]$ & 0 & -10 \\
\hline delta $[\mathrm{mm}]$ & 12 & 7 & delta $[\mathrm{mm}]$ & 2 & 17 \\
\hline delta $[\mathrm{mm}]$ & 6 & 5 & delta $[\mathrm{mm}]$ & 2 & 25 \\
\hline delta $[\mathrm{mm}]$ & -8 & 6 & delta $[\mathrm{mm}]$ & 3 & 7 \\
\hline delta $[\mathrm{mm}]$ & 2 & 6 & delta $[\mathrm{mm}]$ & 2 & 21 \\
\hline delta $[\mathrm{mm}]$ & 0 & 7 & delta $[\mathrm{mm}]$ & 6 & 1 \\
\hline delta $[\mathrm{mm}]$ & -6 & 1 & delta $[\mathrm{mm}]$ & 0 & -9 \\
\hline delta $[\mathrm{mm}]$ & 5 & 1 & delta $[\mathrm{mm}]$ & 0 & -11 \\
\hline delta $[\mathrm{mm}]$ & -6 & -2 & delta $[\mathrm{mm}]$ & -2 & 5 \\
\hline delta $[\mathrm{mm}]$ & 4 & -2 & delta $[\mathrm{mm}]$ & -1 & 1 \\
\hline delta $[\mathrm{mm}]$ & 6 & 2 & delta $[\mathrm{mm}]$ & 1 & 10 \\
\hline delta $[\mathrm{mm}]$ & -7 & -17 & delta $[\mathrm{mm}]$ & -6 & 11 \\
\hline & & & & \\
\hline
\end{tabular}

\begin{tabular}{|r|r|r|r|}
\hline & SDEV [1 sigma] & 6 & 9 \\
\hline $\max$ & 12 & 19 \\
\hline $\min$ & -8 & -26 \\
\hline
\end{tabular}

In general the results were satisfying, and did not undermine any interrelationships between the installations or their clearance to the railway. In the case of the OHLE and WW there was a further stage of manual adjustment built into the items in relation to the bracketry to enable later precise positioning for the rail vehicle. The uncertainties in chainage and angle for the drilling were then obviated by simply enlarging the no drill zone dimensions within the EMT program calculations.

By comparison to manual methods, obviously, first and foremost, the trial and error in finding suitable drilling positions was completely avoided. Also the misinterpretation of setting out marks and any non-aligned or deep enough drilling - which is always a possibility with manual methods was eliminated. This certainty and uniformity of result on site far outweighed any slight lowering of resolution of the positioning caused by using machine guidance instead of protracted direct manual set out.

\section{Operating principles of machine}

To enable the physical drilling works to be undertaken, after the off-site calculation and checking had been undertaken, two mammoth machines were manufactured by Rowa in Switzerland.

The two separate machines were developed with slightly different configurations to accommodate the different spacing of holes and enable safe access and egress past the machines at all times.

Figure 17 below shows a 3-D computer generated model of the machine which housed the drilling arms for the CMS and WW bracketry identifying some of the key components.

Figure 17: A 3D computer generated model of the Drilling Machine One used for CMS and WW Holes

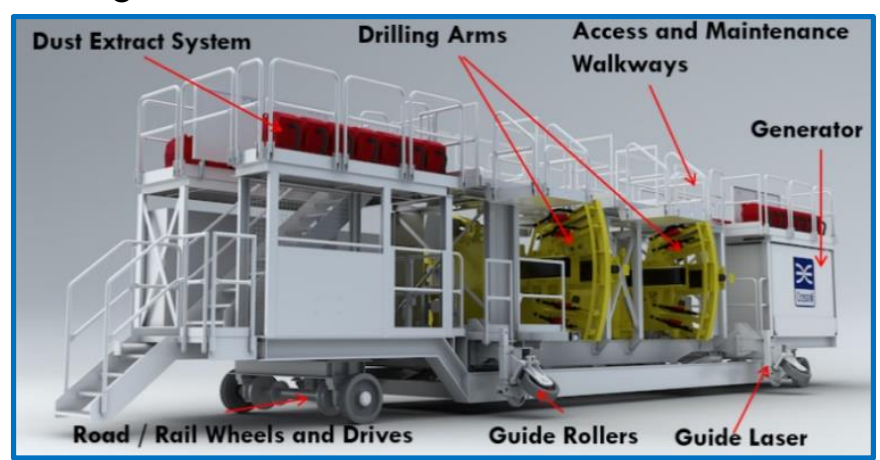

The machines were self-propelled units that could operate in both on-rail and "pre-rail" modes (if M\&E drilling preceded trackwork in the program), Both machines housed a diesel generator on board to power all the tools, lighting, control and hydraulic drives. All movements of the machines were then hydraulically actuated to ensure that the necessary combination of high load and high precision movement were achieved. Operatives attended to the machines from the railhead/depot location on a backup vehicle with welfare, fuel and small consumables at the beginning of the shift and then removing the waste dust bags at the end.

Drilling arms' drives had position sensors installed enabling the machine to be precisely articulated by the control system. The drives were as follows:

- a longitudinal slide which enabled the precise chainage to be obtained

- a rotational drive to enable the precise angle to be obtained

- an extendable section to enable the arm to be pushed against the lining

- linear drives for each individual drill to be progressed to the defined hole depth.

Stock drilling tools were used and housed in a clamping system to ensure that the machine was easily maintainable within the tunnel environment. To control the release of harmful silica dust into the environment each drill was connected to a vacuum unit which came into operation simultaneously during drilling.

To achieve alignment of the machine centreline with the BFC of the tunnel the machine was split into two halves. The lower half contained the drive equipment and was supported from the 
running surface (either first stage slab when pre-rail or the rails themselves). The upper half contained all of the drilling equipment that required fine positioning and was supported by guide rollers which ran along the surface of the tunnel lining. See Figure 18 for a picture of the CMS/WW machine in its operating configuration.

The machine was also collapsible to a form that fitted within the kinematic envelope of the permanent trains so as to enable it to be tracked in and out of the tunnel without clashing with installed services.

Figure 18: Automated tunnel drilling machine working in its operating configuration

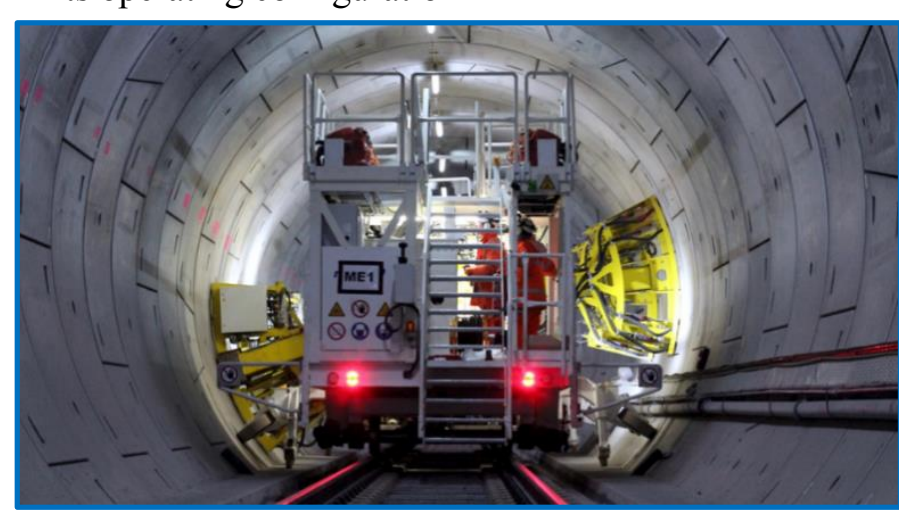

\section{Productivity}

Following the commissioning of the machines an output rate of between $150 \mathrm{~m}$ and $225 \mathrm{~m}$ per shift per machine was consistently achieved with a peak of $270 \mathrm{~m}$ in a single shift. This rate is comparable with the work that could be completed by 20 operatives excluding the additional setting out and marking at height that would have been required for manual drilling.

\section{Conclusions}

The drilling machine project was first and foremost a success in terms of delivering a working solution on site from just a concept in under two years without much in the way of precedent to refer to. Support from the senior management of ATCjv (Alstom, TSO, Costain joint venture) and the client, Crossrail, was a significant factor in the project succeeding.

There was a necessity for the very different departments and disciplines of M\&E, OHLE and Survey to work closely together and, at times, produce additional data and drawings beyond original scope of works in order for the integration to work.

There was also a very strong commercial management of the tender process for the machine manufacture, software and scanning contracts which, given the unprecedented nature of parts of the solution, certainly tested the minds of all of those involved but assured that best value for money was achieved.
The supporting technology, scanning, had, at last, sufficiently matured in terms of processing outputs to not be a point of concern when considering tight timescales from surveying to drilling. Perhaps further developments may be possible in this area with image recognition. However it is the authors' concern that the solution should not become too "black-box" and it should not be overlooked that the relatively easy to understand data inputs and EMT outputs were a cornerstone of the opportunity for thorough first principles checks that debugged and validated the solution.

The production outputs justified the investment in the solution but that evaluation does not account for the benefit of not having to find alternative solutions for manually drilling 250,000 holes safely and accurately in the $42 \mathrm{~km}$ of tunnels.

It was the authors' experience that the small team assembled to operate the machine on site were extremely dedicated and displayed a sense of ownership and responsibility for its success that further minimised problems during production. There seems little doubt that if the drilling had been done manually by a far larger team the amount of quality control challenges would have multiplied.

Because of the relatively uniform nature of the bored tunnel the parameters within which the machines operated were controllable. It is, in fact, an ideal environment in which to substitute an automated system.

Overall it is the authors' belief this drilling machine project has further contributed to the argument that automated solutions, albeit with larger up-front investment and planning, can make a significant difference to the quality of repetitive work and the avoidance of costly H\&S impacts on the workforce. In terms of the Crossrail solution the EMT software and Rowa guidance software are all transferrable to other bored tunnels. Perhaps only the machine diameter and physical arm configurations of the machines themselves would need modification for another project.

\section{References}

Wren T et al. (2016) Delivering optimum results for ATC on Crossrail. Engineering Surveying Showcase October 2016: pp. 12-13.

Website as further information

Crossrail C610 Drilling Machine, GB. See http://www.rowaag.ch/en/referenz-projekte/spezialanlagen/index.html

for further details (accessed 13/01/2019) 